\title{
Raising Awareness about the Preservation and Promotion of the Traditional Cultural Values of Hoi an in the Renovation Process of Vietnam
} Le Thi Hong Van*

Ly Tu Trong College Ho Chi Minh City, Vietnam

DOI: 10.36348/jaep.2020.v04i10.002 $\quad$ | Received: 25.09 .2020 | Accepted: 06.10.2020 | Published: 07.10.2020

*Corresponding author: Le Thi Hong Van

Abstract

With the efforts of authorities at all levels, functional branches, and the support and consensus of the people, especially the support and assistance of international organizations, foreign experts, management heritage management, conservation, and promotion in Hoi An (Quang Nam province) is reaping many important successes. However, for many years, the awareness of preserving and promoting the heritage values of Hoi An has not been enhanced, especially for other tourists. This study analyzes the situation awareness to preserve the cultural values of Hoi An, but work to raise more awareness of the heritage, the values that the heritage brings to the lives of Hoi An people and people nationwide. Since then, proposing solutions to further raise awareness about preserving the traditional cultural values of Hoi An in particular and the traditional heritage of the Vietnamese people in general.

Keyworsds: Awareness, the preservation and promotion, the traditional cultural values, Hoi An, renovation, Vietnam.

Copyright ( 2020: This is an open-access article distributed under the terms of the Creative Commons Attribution license which permits unrestricted use, distribution, and reproduction in any medium for non-commercial use (NonCommercial, or CC-BY-NC) provided the original author and sources are credited.

\section{INTRODUCTION}

Raising awareness about preserving and promoting the traditional cultural values of the Association is one of the important issues in heritage conservation and development. This is the first solution in the system of solutions to preserve and promote the traditional cultural values of Hoi An in the renovation process. In the view of dialectical materialism, awareness is the process of reflecting the creative realism objectively into the human mind, through language and practical activities of production. In the dialectical relationship between perception and reality, awareness plays a very important role. Thanks to scientific awareness, people have determined the right direction to lead all activities properly and effectively on the basis of certain physical conditions, because "all that motivates Human actions are inevitable through their minds [1]". Therefore, in order to further promote the preservation and promotion of traditional cultural values in the renovation process in Hoi An, it is necessary to raise awareness for the entire Party Committee, authorities, and mass organizations. in Hoi An, properly and fully on the role in preserving and promoting traditional cultural values for the process of reforming socio-economic service of Hoi An; thereby creating a unity of awareness and action in the political system of Hoi An. This is also considered as one of the decisive factors in the cultural development, preservation, and promotion of traditional cultural values in Hoi An today.

Along with the renovation process of the country and Quang Nam province, Hoi An city has actively and proactively grasped the undertakings, lines, and policies of our Party and State on cultural development, preservation, and promote the traditional cultural values serving the socio-economic development to the Party committees, authorities, agencies and departments as well as all classes of people in the city; and through propaganda and education, it has contributed to raising awareness in the entire Party Committee as well as the people in the province about the purpose, meaning and content of cultural development, preservation and promotion of values. Traditional culture for the city's renewal process. From there, determine its position, role, and obligations in preserving and promoting the traditional cultural values of Hoi An as well as creating coordination among branches, unions, social organizations, and the people step up the work of preserving, repairing, preserving, and promoting the city's traditional values in the renovation process. However, a part of the population, cadres, and party members in the city are not fully aware of the meaning, position, and importance of preserving and promoting traditional cultural values. preserving and promoting traditional cultural values, or 
separating the preservation and promotion of traditional cultural values, economic development, absolute economic, pursuit of pure economic interests. light cultural factor, thereby leading to a decrease in the sense of preserving and promoting cultural traditional cultural values in socio-economic fields in the process of innovation, making The socio-economic development still has many uncertainties and deviations as presented in the current situation. This, the Party Committee of Hoi An city frankly acknowledged:

"The State apparatus's thinking, level and awareness of urban management have not met the requirements and are weak in presence; the planning work is still passive, embarrassing, the planning management is still emotional, obstructing the development of the city; A part of the population's awareness of heritage management, protection and construction is not high [2]".

\section{LITERATURE REVIEW}

Since the Communist Party of Vietnam was born and became the leading force of the country, in the resolutions and principles of the Party, there is a consistent policy of preserving and promoting the traditional cultural values of the nation. In 1945, after the successful August Revolution, our Party and State paid great attention to preserving the national cultural heritage. On November 3, 1945, President Ho Chi Minh signed and announced the Decree No. 65/SL on the conservation of historical monuments across the country of Vietnam. After Decree No. 65/SL, October 29, 1957, Decree No. 519-TTg on the protection of historic monuments and landscapes issued by the Prime Minister has created favorable conditions for the culture and sports industry. conduct a general inventory of historical, cultural and scenic relics in provinces and cities throughout the North; help protect the most important monuments of the country. The Ordinance on the protection and use of historical and scenic relics, announced by the State Council on April 4, 1984, demonstrated the Party and State's interest in the preservation of cultural heritage. nationalization. These decrees and ordinances represent our Party's theoretical thinking about the preservation of cultural heritages at specific times and circumstances, which are always developed, consistent with economic and major conditions. governance - society in specific historical stages of the country.

The comprehensive national renewal is an important turning point in the cause of national development [3]. The most profound changes start in the economic field, where, instead of the bureaucratic and subsidized economy, our Party and State have advocated the development of a socialist-oriented market economy, there is state management. In order to have revolutionary changes in the political - economic social and cultural life, our Party and State have issued a series of guidelines, orientations, laws and policies; the documents have a profound impact on the process of preserving, protecting and promoting the values of the national cultural heritages.

Our Party's theoretical thinking on preserving and promoting cultural heritages has been increasingly perfected through the Party's documents and resolutions during the period of comprehensive national renewal. At the 6th Congress, for the first time, our Party raised the policy of socialization of cultural activities: "Together with the people, the State builds the necessary technical and material foundations for culture and arts, keeping preserving and embellishing historical and cultural relics [3]" and "Preventing commercial trends and other negative phenomena [3]" in the cultural field; At the same time, he emphasizes to be determined", etc. against the ruins of feudalism, colonialism, and bourgeoisieism. Failure to the plot and activities of hostile forces turns culture, culture into a means of spreading pessimism and depraved lifestyle. Eliminate superstition, superstition, profane [3]". These important ideas were developed more specifically in the 7th National Congress Document, the 4th Central Resolution Session VII, which was completed in Central Resolution 5, Session VIII and further affirmed in the Conclusion of the Conference. the tenth time of the IX Central Executive Committee. Document of the 7th Congress of the Party affirms: "Continue to build and develop the cultural cause of Vietnam, preserve and promote the fine cultural traditions of all ethnic groups, absorb human culture [4]".

Concretizing the views of the Party, especially the Resolution of the 7th Congress, Article 30, the 1992 Constitution clearly states that: "The State and society preserve and develop Vietnamese culture: the nation, modernity, humanities; inherit and promote the values of the cultures of Vietnamese nationalities, the thought, morality and style of Ho Chi Minh; absorb the quintessence of human culture; promote all creative talents among the people. The state uniformly manages the cultural cause. It is strictly forbidden to spread depraved and reactionary ideas and cultures; eliminate superstition, profane [5]".

On January 14, 1993, the Fourth Conference of the 7th Central Committee meeting issued Resolution No. 04-NQ/HNTW on a number of cultural and artistic tasks in the coming years. Among the six orientations on ideological work, one major orientation is cultural development, with two basic contents promoting national cultural identity and absorbing the cultural essence of humanity.

An important document of the Communist Party of Vietnam that has influenced the general cultural development today is the Central Resolution, Session VIII. This is a resolution on the cultural strategy of our Party in the period of accelerating industrialization and modernization. The resolution 
emphasizes: "The general direction of our country's cultural cause is to promote patriotism and the tradition of national solidarity, the sense of independence, selfreliance, self-reliance to build and develop Vietnamese culture. The South advanced, imbued with national identity, absorbed the quintessence of human culture, made the culture permeate the entire social life and action, into each person, each family, each collective and community VND, each residential area, in each field of life and human relations, creating in our country a high spiritual life, high intellectual level, scientific development, effectively serving the cause. industrialization and modernization for the goal of a rich people, a strong country, a fair and civilized society, to step firmly towards socialism [6]".

According to Central Resolution VIII, 5th term, national cultural identity "includes sustainable values, the essence of the ethnic communities in Vietnam has been cultivated through thousands of years of struggle history. build water and preserve it [6]". Accordingly, protecting the cultural identity and the value of the national cultural heritages is to protect the national elites formed and preserved over thousands of years of building and defending the country. The protection of national cultural identity must be associated with international exchange, absorbing the quintessence of human culture, enriching and enriching Vietnamese national culture. Central Resolution 5, term VIII affirms: "The protection of national identity must be associated with expanding international exchange, selectively absorb the good, the progress in the cultures of other ethnic groups. Preserving national identity must go hand in hand with fighting backwardness, obsolescence, old customs and habits [6]". At the same time, the Resolution also issues and requires protection of cultural heritage including traditional culture and revolutionary culture, tangible culture and intangible culture. The resolution writes: "Cultural heritage is an invaluable asset, connecting the ethnic community, is the core of the national identity, the basis for creating new values and cultural exchange. Attaching utmost importance to preserving, inheriting and promoting traditional cultural values (scholar and folk), revolutionary culture, including both tangible and intangible cultures [6]".

At the $\mathrm{X}$ Congress, our Party continued to emphasize the issue of preserving and promoting cultural heritage values in the cultural development of the country. The resolution of the congress clearly states: "Continuing to invest in the preservation and embellishment of historical relics of the revolution and the resistance, the tangible and intangible cultural heritages of the nation, cultural values. art, language, and fine customs of the community of ethnic groups. Preserve and promote folk culture and arts. Harmoniously combine the protection and promotion of cultural heritages with economic and tourism development activities [7]'. The Party Congress XI not only continued to affirm the need to preserve and promote the value of the nation's traditional and revolutionary cultural heritages, but also specify specific requirements in preserving the value of the cultural assets, especially the Vietnamese language and languages and scripts of different ethnic groups. The resolution clearly states: "Protect the innocence of Vietnamese, etc develop and implement conservation policies, promote cultural values, languages and scripts of ethnic minorities [8]".

Following the spirit of Congress $\mathrm{X}$, Congress XI, Resolution of the 9th Central Party, session XI supplemented and concretized the task of preserving and promoting the national cultural values. Accordingly, conservation and promotion of cultural heritages must be associated with tourism and economic development. The resolution clearly states: "Preserve and embellish typical historical-cultural relics, serving traditional education and economic development; linking conservation and promotion of cultural heritages with tourism development" [9]. In particular, with the impact of globalization, increasingly deep international integration and the development of the scientific and technological revolution, the issue of preserving and promoting the nation's cultural heritages, The hybridization and abuse were put into one of six tasks by Central Resolution 9, Session XI to build and develop Vietnamese culture and people. The resolution clearly states: "Development goes hand in hand with preserving the purity of Vietnamese; overcome the abuse of foreign languages. Preserve and promote the cultural heritages of ethnic minorities, especially their voices, scripts, costumes, and traditional festivals; positive cultural values in religion and beliefs" [9]. It can be affirmed that the issue of preserving and promoting the national cultural heritages has been mentioned for a long time, but this is the first time, in the Party's theoretical thinking, this issue has been specifically mentioned. and most complete. If the previous resolutions, our Party only mentioned the folk cultural heritages, languages and scripts, in the 9th Central Resolution, Session XI, our Party mentioned the preservation of the Active cultural properties in religion and beliefs.

The Party's point of view and the State's policies in the period of comprehensive national renewal, especially the development of the Party's theoretical thinking on conservation and promotion of national cultural heritages It has only theoretical significance but also has a great effect in preserving and promoting the values of cultural heritages, preventing degradation and abuse, and taking advantage of historical and heritage sites. the culture of the nation. At the same time, it has a strong impact on the cause of building an advanced Vietnamese culture, imbued with national identity, creating a driving force for the development of the tourism industry "a smokeless industry" that brings profits to high sacrifice for the country. 
Situation of Heritage Protection Awareness in Hoi An

With the meaning of living heritage area, the change in people's lifestyle is the biggest challenge, because now more than $82 \%$ of the monuments in the old town are owned by the people [2]. Therefore, the process of preserving Hoi An heritage also faces many difficulties and challenges. The renovation and repair of monuments recently happened at a too fast speed, for business purposes, commercial activities, including the needs of modern life, but the renovation, repair, using the house - relic has many mistakes in principles of conservation, violating the historical nature and originality of the monument.
The misuse of relics, the purchase, sale, and transfer of relics in some cases have turned old houses associated with traditional family cultural values for generations in Hoi An into pure establishments. drug specializes in displaying, buying and selling goods. The situation of changing owner from long-time homeowners to new owners from elsewhere is becoming more common. These actions are harming the traditional cultural values of Hoi An about lifestyle, cultural activities, customs, behavior, cuisine, etc. Over the past many years, the number of families has reached on cultural criteria is increasing (Table 1), however, awareness of heritage protection is still limited due to many objective and subjective reasons.

Table-1: Number of households, communes / wards / towns meeting cultural standards

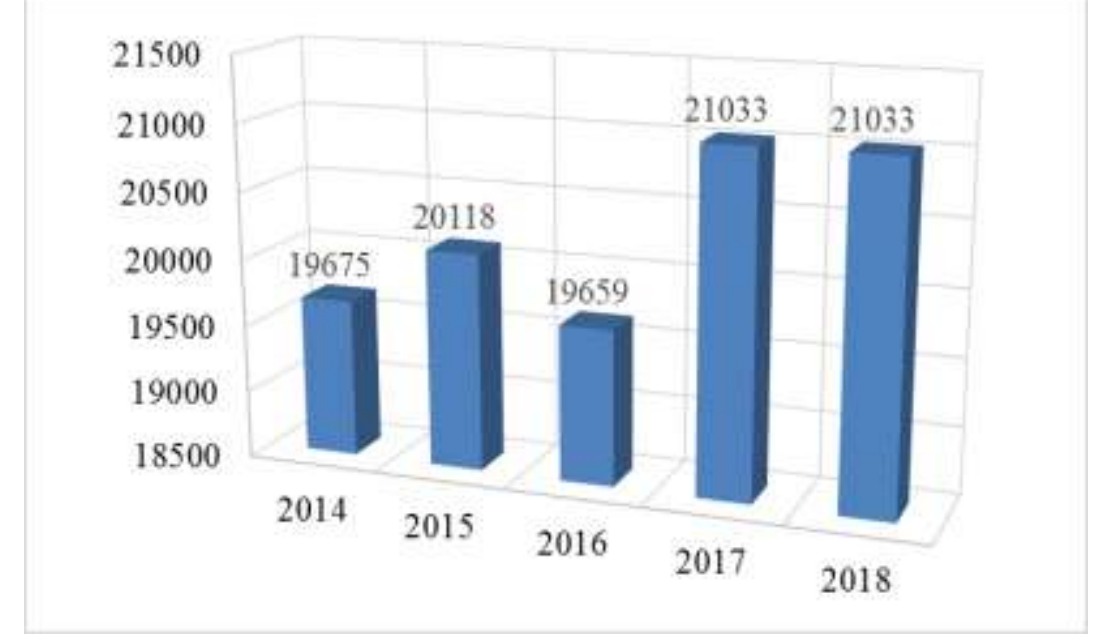

Source: Hoi An Provincial Statistical Office in 2019

During the development process, the benefits to the relic owners are not really fair. The difference in income and benefits from the heritage area is happening between houses on the main streets and houses located in masterpieces, alleys, between the old town and the suburbs. Obviously, if the responsibility to preserve the heritage is the same, the benefits from the heritage must also be dealt with in a harmonious and reasonable manner.

Although being concerned from quite early, but due to many reasons, many intangible cultural values in Hoi An have either been forgotten or denied, so they have been lost and lost a lot. Some traditional craft villages only operate in moderation. Some elderly artists have passed away one by one, etc. Many types of folk performances are in danger of dying, etc. Many policies and policies on conservation and promotion of intangible cultural values has been included in the strategy but the scale is not adequate; investment projects are inclined to exploit for economic purposes but not promote and exploit cultural identity, not promote the strength and activeness of the community.

\section{Solutions to Raise Awareness on Heritage Protection in Hoi An}

The awareness of the role and meaning of preserving and promoting traditional cultural values is still so limited among the people and in a part of officials and party members in the city is one of the reasons. leading to not really promoting the meaning, the role of preserving and promoting traditional cultural values still has many shortcomings and limitations. Therefore, to raise awareness for the entire Party Committee, authorities and departments of Hoi An City in a deeper and more complete manner about the role of preserving and promoting the traditional cultural values of the Association. An really becomes the foundation and driving force in the innovation process, it is necessary to focus on widely propagating the views, content, solutions for cultural development, as well as preserving and promoting cultural values. system to agencies, organizations, social forces, people, in order to create a change in awareness and action in the whole political system of the province. Besides, it is necessary to continue to mobilize and encourage all classes of people to participate in the protection, preservation and promotion of heritage values; to further step up the socialization in heritage conservation and promotion. At the same time, propagate and mobilize people to 
consciously maintain a friendly and simple lifestyle; Because each component in that system has a different important role and position, but needs synergies, forming synergy, bringing development and development to preserve and promote cultural values. tradition in the renovation process of Hoi An to success, towards the development goal for people. The education to raise awareness of the role and importance in preserving and promoting traditional cultural values in the renovation process in Hoi An needs to be carried out throughout the whole system. Political and social city:

Firstly, to raise awareness about the preservation and promotion of traditional cultural values in the renovation process for the Party Committee and the government of Hoi An city. In order to fully realize the Party's viewpoints and lines on preserving and promoting the traditional cultural identity in the process of changing, from which to well implement the task of preserving and promoting cultural values Traditionally serving the socioeconomic development in the renovation cause in Hoi An, the first solution is to raise awareness in the whole political system, but first of all to grasp and raise awareness in The entire Party Committee and government apparatus of the City, because the Party Committee and the municipal government agencies are the brain, which is the place to guide the views, make policies, guidelines and plan mechanisms. socioeconomic development books of the province in general, local cultural development in particular. This is also the place to direct and organize the implementation of the Party's guidelines and policies and the State's policies on the implementation of the province's socioeconomic development strategic tasks, in accordance with the characteristics and conditions. local specifics; In addition, raising awareness of the Party Committee and the City government is also the driving force, contributing to promoting the spirit of dare to think, dare to do, boldly change the mode of operation, from production, business to Organizing and managing the society, in order to operate more and more effectively, to properly enrich themselves and the society, including preserving and promoting traditional cultural values. In practice, the leadership's awareness of the preservation and promotion of traditional cultural values in the innovation process is reflected in the socio-economic development mission goals and institutionalized by Specific policies and laws suitable to the local conditions and practical situation of the unit in order to enhance the preservation and promotion of traditional cultural values for socio-economic service in the public. Comprehensive national renewal. From practical leadership, the Party Committee of Hoi An city draws lessons from:

"Wherever the Party organization is strong, it can mobilize the strength to fulfill its tasks well, all difficulties can be overcome; in which the political bravery, will and organizational capacity of the staff is the key factor. The leader with high intelligence, capacity, enthusiasm and responsibility can gather the consensus of cadres, party members and people; know how to listen and correct mistakes, democracy, creativity, the power of the people are promoted, the people's peace and confidence are strengthened [2]."

Therefore, the solution to raise awareness for the Party Committee and the government of Hoi An city about the role, meaning and importance of preserving and promoting traditional cultural values in the renovation process. in Hoi An is a prerequisite solution. In particular, the Party agencies and the government of Hoi An city, at all levels need to fully and deeply grasp the viewpoint "Development of culture - the spiritual foundation of the society", "building the first Vietnamese culture. advancing, imbued with national identity, meeting the requirements of social and human development in the conditions of accelerating industrialization, modernization and international economic integration" [7] of the Party, making an important contribution in the process of socio-economic development; investment in culture is investment for development, aiming to create a positive change in awareness and action of the entire political system in performing tasks; promote dynamism, creativity, will and determination to put guidelines and policies into practice. On the other hand, the perception of the role in preserving and promoting traditional cultural values in the renovation process must be consistent in the entire socio-political system of the City, avoiding the situation of one-to-one action. arbitrary way, lack of synchronization among departments in the implementation process.

Thus, the consistent, comprehensive and regular awareness among leaders, authorities and sociopolitical organizations is the task of preserving and promoting traditional cultural values in the process. City renewal is essential. Party agencies, authorities and departments, branches of the City are responsible for setting guidelines, mechanisms and policies, and at the same time organizing and guiding social actors, arousing all resources in society. In order to further improve the preservation and promotion of traditional cultural values in Hoi An in the renovation process for the rapid and sustainable socio-economic development of the city. All acts of distorting the cultural development mechanism for the sake of individuals, groups, falsifying or distorting policy policies need to be strictly punished.

Secondly, to raise awareness of the preservation and promotion of traditional cultural values in the renovation process for the people of Hoi An City. According to the basic principles of historical materialism, masses of people are the creators of history. Hoi An people are the creator of traditional 
culture as well as the subject preserving and promoting those values. Therefore, considering the same undertakings, lines and resolutions, whether or not they are effective, it is ultimately due to the masses of the people. When they understand the role and meaning in preserving and promoting traditional cultural values in the renovation process, people will actively participate in the preservation, improvement and development. As well as effectively exploiting the traditional cultural heritages of the locality, meeting the development and socio-economic development of the city. People's awareness of preserving and promoting traditional cultural values also helps them understand that, in order to ensure social security in the future, the preservation and promotion of traditional cultural values are not it is only personal responsibility but also social responsibility; culture is the social spiritual foundation, both the goal and the driving force for the rapid, harmonious and sustainable development of individuals and society, which will be an important premise to guide and motivate people and the commune. The Association has the initiative, self-awareness, and creativity, etc. in practical activities to enhance the role of culture for the goal of building an eco-cultural tourist city. As C. Marx stated: "The material force can only be beaten by physical forces, but logic will also become a material force, once it penetrates into the masses" [1], therefore, when people's perception of Hoi An is correct, it will become a guideline for their practical activities, becoming a great driving force, creating a driving force. push the city's socio-economic development.

For that reason, to deepen people's awareness of the role and meaning in the work of preserving and promoting traditional cultural values for social life, meeting the requirements of global renewal. Hoi An representatives, the city authorities need through the mass media to constantly propagate and disseminate guidelines, policies and orientations on the meaning and importance of culture and public. cooperation to preserve and promote traditional cultural values in the renovation process. That, as Ho Chi Minh said, the purpose of propaganda is: "Bring something to the people understand, people remember, people follow, people do" [10]. Therefore, the propaganda must make all people aware of the role of building and developing national culture as the foundation and driving force for social development, effectively serving in the renovation process. On the other hand, Hoi An also needs to have a consistent awareness that propaganda and dissemination of the role of culture, preserving and promoting traditional cultural values in Hoi An is a necessary and long-term work. long, often with many different modes and means, such as propaganda through media channels, newspapers and radio stations. At the same time, Hoi An needs to build and develop a network of propaganda officers, rappers, and communicators with clear political qualities, morals, and a firm grasp of the content of undertakings, policies and resolutions of The Party and State on cultural construction and development, as well as the role of cultural preservation and promotion in the renovation process of Hoi An. Central media and press agencies, as well as the radio and radio system from Hoi An City to the grassroots level, need to build and effectively implement the column "Bringing the Party Congress to life". Along with the propaganda, the publicization of planning, plans, activities to preserve and develop culture under the guidelines of Party organizations, authorities at all levels, coordinate with mass organizations to improve highly preserving and promoting traditional cultural values in Hoi An in the renewal process for all people to actively participate in the conservation and creation of cultural values in a new context for the future of a sustainable society.

Along with that, in order to raise people's awareness of preserving and promoting traditional cultural values, Hoi An should focus on investing in upgrading the quality of school education, because this is the pillar of development. development, is the shortest way to convey traditional culture into the younger generation. Education and training in Hoi An need to regularly combine activities of preserving and promoting traditional cultural values with school education. Putting into educational programs at all levels the content, meaning and role of preserving and promoting traditional cultural values for social life, widely disseminating research results on culture and margins. compose and system into documents and teaching materials at school. Regularly coordinate with relevant organizations to organize contests to learn about traditional culture in Hoi An, bring into the study program of students, students periodically organize for them to visit and participate. extracurricular activities at cultural heritages, thereby raising the young generation's awareness of the nation's traditional cultural history. At the same time, Hoi An needs to focus on improving the teaching quality of subjects such as the history of Vietnamese national culture and local cultural history, helping the young generation to have an understanding, pride in their roots and values of the national culture and Hoi An, from which we know how to respect and promote cultural values that our fathers diligently embellished into practical activities. Hoi An city also needs to compile educational materials, open classes to foster knowledge about culture, the role of culture in development, the role of local culture as well as training courses on points and policies for cultural development of the Party and State of Vietnam and of the city for the contingent of cadres, party members, the contingent of artists and artists, etc. who directly work to preserve and promote culture tradition in Hoi An city.

In addition, the city government needs to promote the education of a sense of preserving and promoting traditional cultural values associated with the sense of economic enrichment for the people of Hoi An. 
Awareness of preserving and promoting traditional cultural values through economic activities. However, it is imperative that the people of Hoi An not follow the non-cultural economic growth, get rich by "selling cheap" the traditional culture of the nation or opposing the traditional cultural values of the people nation.

\section{CONCLUSION}

Implementing people's awareness raising is an important long-term goal such as: The program of bringing heritage education into schools; Strengthen the popularization of laws for people on cultural conservation, heritage protection, avoid infringement of architectural works, infringe upon forest products exploitation in the restricted forest area, support livelihoods for people transforming the economic model, at the same time implementing commitments to link responsibilities and benefits with the people through poverty reduction support policies and welfare programs for people to inherit.

Today, development associated with globalization - integration is seen as a process, a trend, the problem of how cultural heritage develops in the direction of modernity but still retains cultural values. has its own local identity, it is necessary to recognize, behave and manage each cultural and natural heritage as a "living museum".

Thus, only the correct perception can have the right policy, plan, direction and right method and action. From there, define the common responsibility and responsibility of each person in preserving and promoting traditional cultural values, serving the socioeconomic development in the renovation process in Hoi
An in the process of renew. In order to turn awareness into life, they must be expressed through specific undertakings, mechanisms, policies and programs, thereby further enhancing the preservation and promotion of literary values. traditional chemistry in the renovation process in Hoi An today.

\section{REFERENCES}

1. Marx, K \& Engels, F. (1999). The complete episode, episode 36. Hanoi: National Politics.

2. Quang Nam Provincial Party Committee, Hoi An City Party Committee. (2015). Report on socioeconomic situation of Hoi An city.

3. Communist Party of Vietnam. (1986). Document of the Party VI. Hanoi: The Truth.

4. Communist Party of Vietnam. (1991). Document of the Party VII. Hanoi: National Politics.

5. National Assembly of the Socialist Republic of Vietnam. (1992). Constitution of the Socialist Republic of Vietnam. Hanoi: National Politics.

6. Communist Party of Vietnam. (1998). Document of the Fifth Conference of the Central Executive Committee term VIII. Hanoi: National Politics.

7. Communist Party of Vietnam. (2006). Document of the Xth National Congress of Delegates. Hanoi: National Politics, Hanoi.

8. Communist Party of Vietnam. (2011). Document of the XI National Congress of Delegates. Hanoi: National Politics.

9. Communist Party of Vietnam. (2014). Document of the Ninth Conference of the XI Central Committee, Party Central Office, Hanoi.

10. Minh, H. C. (1995). The complete episode, episode 8. Hanoi: National Politics. 